\title{
Novel Use of Catheter Mount as an Alternative to T-piece
}

\author{
Abhijeet Anand ${ }^{1} \oplus$, Rajesh Panda ${ }^{2} \odot$, Saiteja Kodamanchili ${ }^{3} \odot$, Saurabh Saigal ${ }^{4} \odot$, Gowthaman TB $^{5} \odot$, Krishnkant Bhardwaj $^{6} \odot$
}

\begin{abstract}
Catheter mounts with swivel connectors are used to attach the endotracheal tube to the ventilator circuit, dampening jerks and drags and increasing patient comfort. We suggest a unique application of catheter mount as T-piece for weaning, eliminating the need for a single inventory purchase and repurposing a previously used item for a new use, lowering the financial burden on patients. In our ICU, catheter mounts are being used as an alternative to T-piece for 30-minute weaning trials following successful SBT trials to evaluate patients' response to Zero PEEP (ZEEP) and therefore the probable occurrence of alveolar derecruitment to decrease extubation failure.

Keywords: Catheter mount, Spontaneous breathing trial, T-piece, Weaning from mechanical ventilation.

Indian Journal of Critical Care Medicine (2022): 10.5005/jp-journals-10071-24114
\end{abstract}

The T-piece spontaneous breathing trial (SBT) is still used in mechanical ventilation weaning as a rigorous assessment technique for determining readiness to extubate. ${ }^{1}$ The T-piece used in intensive care units (ICUs) is a modified form of Ayre's T-piece, which offers a low-resistance open circuit with corrugated reservoir tubing and fresh gas supply at diagonally opposite ends, with the patient connection perpendicular to both. ${ }^{2}$ Weaning on T-piece produces near-normal stress for any patient since it lacks positive end expiratory pressure (PEEP) and pressure support and so increases the work of breathing as compared to weaning on pressure support ventilation (PSV). T-piece, being a more strenuous exercise, increases the rate of weaning trial failure and hence delays extubation; nevertheless, weaning on PSV has a higher incidence of extubation failure. ${ }^{3}$ Reintubation, in and of itself, increases morbidity and mortality. ${ }^{4}$

Catheter mounts with swivel connectors are used to attach the endotracheal tube to the ventilator circuit, dampening jerks and drags and increasing the patient comfort. We propose a novel usage of a catheter mount as a T-piece for weaning, which removes the need to purchase the original T-piece as inventory by reusing a previously used item for a new function, hence reducing the cost burden on patients. In our ICU, catheter mounts are being used as an alternative to T-piece for 30 minute weaning trials following successful SBTs to evaluate patients' response to zero peep zero end expiratory pressure (ZEEP) and therefore the probable occurrence of alveolar derecruitment to decrease extubation failure.

After removing the cap, the flowmeter's oxygen flow is connected to the catheter mount's suction port as shown in Figure 1. Like a T-piece, the corrugated tubing serves as a reservoir. Because the catheter mount diameter is greater than the diameter of the endotracheal tubes used, the resistance of the circuit is largely determined by the narrowest portion, which happens to be the endotracheal tube itself. As the relationship is direct and linear according to the Hagen-Poiseuille equation, the resistance owing to the length of the catheter mount is also low. In resource-constrained settings, employing a catheter mount instead of T-piece achieves the same goal at a lower cost.

\section{ORCID}

Abhijeet Anand 으 https://orcid.org/0000-0001-6498-5388
${ }^{1-6}$ Department of Anaesthesia and Critical Care, All India Institute of Medical Sciences, Bhopal, Madhya Pradesh, India

Corresponding Author: Abhijeet Anand, Department of Anaesthesia and Critical Care, All India Institute of Medical Sciences, Bhopal, Madhya Pradesh, India, Phone: +919608443833, e-mail: abhijeet.anand@ hotmail.com

How to cite this article: Anand A, Panda R, Kodamanchili S, Saigal S, Gowthaman TB, Bhardwaj K. Novel Use of Catheter Mount as an Alternative to T-piece. Indian J Crit Care Med 2022;26(2):246-247.

Source of support: Nil

Conflict of interest: None

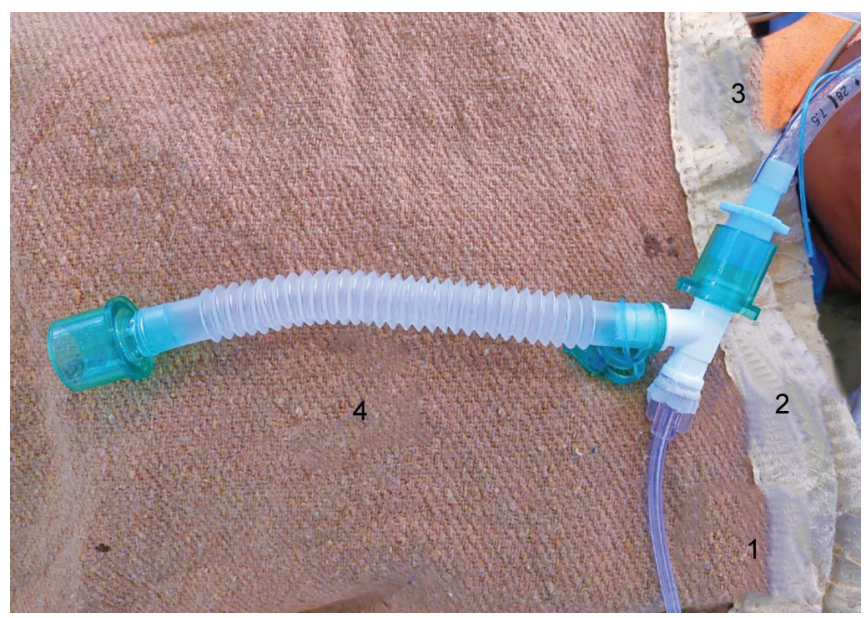

Fig. 1: (1) Oxygen from flowmeter; (2) Suction port with the cap removed attached to oxygen supply; (3) Endotracheal tube with $15 \mathrm{~mm}$ connector; and (4) Catheter mount with corrugated tubing

Rajesh Panda @ https://orcid.org/0000-0001-7123-876X

Saiteja Kodamanchili $\odot$ https://orcid.org/0000-0003-1033-0321

Saurabh Saigal @ https://orcid.org/0000-0002-2364-2271

Gowthaman TB • https://orcid.org/0000-0002-0301-3793

Krishnkant Bhardwaj $\odot$ https://orcid.org/0000-0002-2207-0654

o The Author(s). 2022 Open Access This article is distributed under the terms of the Creative Commons Attribution 4.0 International License (https://creativecommons. org/licenses/by-nc/4.0/), which permits unrestricted use, distribution, and non-commercial reproduction in any medium, provided you give appropriate credit to the original author(s) and the source, provide a link to the Creative Commons license, and indicate if changes were made. The Creative Commons Public Domain Dedication waiver (http://creativecommons.org/publicdomain/zero/1.0/) applies to the data made available in this article, unless otherwise stated. 


\section{References}

1. Burns KEA, Soliman I, Adhikari NKJ, Zwein A, Wong JTY, GomezBuiles $C$, et al. Trials directly comparing alternative spontaneous breathing trial techniques: a systematic review and meta-analysis. Crit Care 2017;21(1):127. DOI: 10.1186/s13054-017-1698-x.

2. Harrison GA. Ayre's T-piece: a review of its modifications. Br J Anaesth 1964;36(2):115-120. DOI: 10.1093/bja/36.2.115.

3. Sklar MC, Burns K, Rittayamai N, Lanys A, Rauseo M, Chen L, et al. Effort to breathe with various spontaneous breathing trial techniques. A physiologic meta-analysis. Am J Respir Crit Care Med 2017;195(11):1477-1485. DOI: 10.1164/rccm.201607-1338OC.

4. Epstein SK, Ciubotaru RL. Independent effects of etiology of failure and time to reintubation on outcome for patients failing extubation. Am J Respir Crit Care Med 1998;158(2):489-493. DOI: 10.1164/ ajrccm.158.2.9711045. 